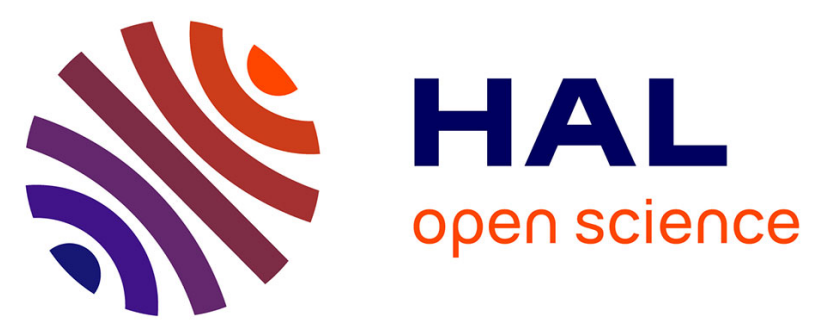

\title{
A Design Method for Product Upgradability with Different Customer Demands
}

Masato Inoue, Shuho Yamada, Tetsuo Yamada, Stefan Bracke

\section{To cite this version:}

Masato Inoue, Shuho Yamada, Tetsuo Yamada, Stefan Bracke. A Design Method for Product Upgradability with Different Customer Demands. 11th IFIP International Conference on Product Lifecycle Management (PLM), Jul 2014, Yokohama, Japan. pp.91-100, 10.1007/978-3-662-45937-9_10 . hal01386479

\section{HAL Id: hal-01386479 \\ https://inria.hal.science/hal-01386479}

Submitted on 24 Oct 2016

HAL is a multi-disciplinary open access archive for the deposit and dissemination of scientific research documents, whether they are published or not. The documents may come from teaching and research institutions in France or abroad, or from public or private research centers.
L'archive ouverte pluridisciplinaire $\mathbf{H A L}$, est destinée au dépôt et à la diffusion de documents scientifiques de niveau recherche, publiés ou non, émanant des établissements d'enseignement et de recherche français ou étrangers, des laboratoires publics ou privés.

\section{(c)(1)}

Distributed under a Creative Commons Attribution| 4.0 International License 


\title{
A Design method for product upgradability with different customer demands
}

\author{
Masato Inoue ${ }^{1}$, Shuho Yamada ${ }^{1}$, Tetsuo Yamada ${ }^{2}$, Stefan Bracke ${ }^{3}$, \\ ${ }^{1}$ Department of Mechanical Engineering Informatics, Meiji University, Japan \\ ${ }^{2}$ Department of Informatics, The University of Electro-Communications, Japan \\ ${ }^{3}$ Chair of Safety Engineering and Risk Management, University of Wuppertal, Germany \\ ${ }^{1} \mathrm{~m} \_$inoue@meiji.ac.jp
}

\begin{abstract}
A sustainable society requires changes in the traditional paradigm of mass production and consumption. Products such as personal computers and smartphones are discarded even though they are fully functional. This paper proposes a design method for product upgradability which satisfies various different customer demands to increase the product value and extend the value lifespan by exchanging components closely related to its deterioration in value. In addition, this paper also proposes a method that can specify future product performances, effective upgradable product components, and the side effects of upgrade on other product components. Finally, this paper discusses the applicability of our proposed design method by considering a vacuum cleaner and various different customer demands.
\end{abstract}

Keywords: Product upgradability, sustainability, customer demands, set-based design.

\section{Introduction}

The change of traditional paradigm of mass production and consumption is required for a sustainable society. Companies and nations are required to reduce their environmental loads [1]. Therefore, environmentally conscious product design is essential. Some of these design methods such as $3 \mathrm{R}$ including reuse, reduce and recycle, and upgradable product design method have been studied [2]. The upgradable product design method is intrinsically executed prior to the disposal of products. Shimomura et al. [3] proposed a method for upgrade planning based on the prediction of customer demands. Fukushige et al. [4] developed a prototype system for product upgradability based on 3D-CAD. However, the method nearly addresses only physical product performance without quantitative considerations of requirements such as cost and environmental load. Thus, this paper focuses on an upgradable product design method, which can treat concurrently physical product performance, environmental loads, and product cost. This method also considers uncertain product 
requirements and design information needed in the future at the time of upgrade. The authors assume that customers discard their products when the perceived value of their present product has deteriorated with time below a certain level relative to the perceived value of new products in the market. In addition, this paper also proposes a method that can specify future product performance and functions, effective upgradable product components, and the side effects of upgrade on other product components. Finally, this paper discusses the applicability of our proposed design method by applying to a design problem of a vacuum cleaner design problem with different customer demands.

\section{A Design Method for Product Upgradability}

\subsection{Purpose and procedure of the method}

A design method for product upgradability seeks to design products that are capable of being adapted to future enhancements of product performance and functions at the early phase of design by predicting those product performance and functions that will be required at the time of upgrade. There are two basic classes of this method as follows:

(a) Upgrade by exchanging components

(b) Upgrade by adding components or modifying the structure of the product

This study focuses on the former class of the method (a). Because future enhancements of product performance and functions eligible for upgrade are to be predicted, the proposed method must include uncertain design information. Here, the uncertain design information is represented as a range value, and a preference setbased design (PSD) method [5, 6] is applied to estimate future enhancements of product performance and features eligible for upgrade. The PSD method can obtain a ranged set of design solutions. Figure 1 shows the procedure of the proposed method.

This paper defines two product lifetimes: durable life and value life [7]. The durable life is a measure of the duration over which the failure rate of a product or component remains below a defined threshold. Conversely, the value life is a measure of the duration that the product value perceived by the consumer remains above a defined threshold. Products such as personal computers and smartphones are usually discarded even though they are fully functioning. This situation derives from the condition where the value life is shorter than the durable life. Therefore, the primary purpose of our method is to reduce the extent of product disposal and the resulting environmental load by increasing the value life of products by exchanging components that have a relatively short value life or by adding new components in accordance with the description. 


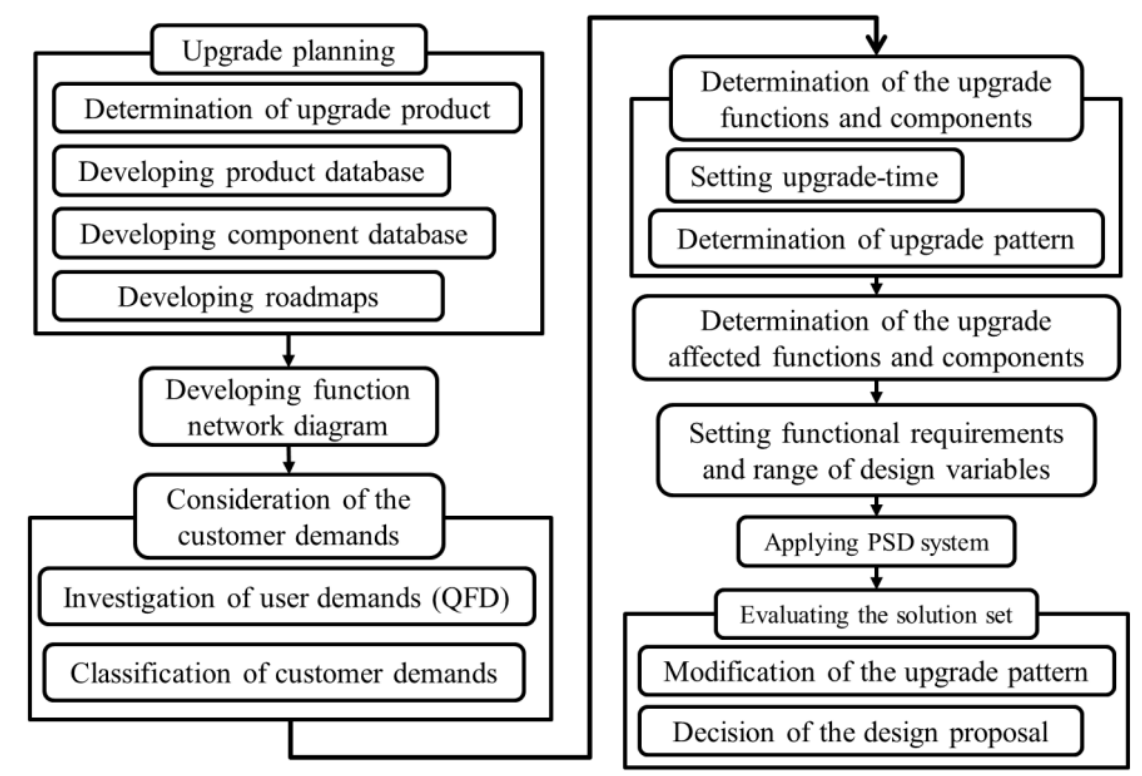

Fig. 1. Procedure of the proposed upgradable design method.

\section{$2.2 \quad$ Upgrade planning}

Here, the authors establish the criterion of the upgrade time. Definition of the upgrade time is based upon several factors such as product upgrade cycle, disposal cycle, or administrative strategy. In addition, the product and component databases are created. These databases contain manufacturers, model numbers, launch times, and product and component performance and/or design variables such as capacity of storage, weight, and dimension. Based on these databases, the authors create product and component roadmaps that evaluate the temporal distributions of performance criteria and/or design variable values. The upgrade time and the product and component roadmaps are used for configuring the performance requirements of the products and components. Under conditions where a product has not yet been launched, roadmaps of similar products can be used for market prediction and for configuring performance requirements.

\subsection{Developing the function network}

A function network diagram illustrates the input and output relationships between performance criteria and product components. This diagram is used for the analysis of upgrade components. Figure 2 provides an example of a function network diagram for a vacuum cleaner. In this diagram, performance criteria and product components are represented by the individual graphics. The positive parameters are indicative of a 
condition where a higher or larger value represents better performance. Conversely, negative parameters are indicative of a condition where lower or smaller values represent better performance. The input-output relations between performance criteria and product components are connected by straight lines, and relevant design variables are described on these lines. Therefore, designers can easily search for components that are related to upgrade performance by following the input-output lines.

In case of a vacuum cleaner (cf. Figure 2), for example, the suction power is the chosen target for upgrade performance. The pertinent components affecting that performance are motor, turbine fan, body, or power unit. They represent candidates with regard to an upgrade possibility.

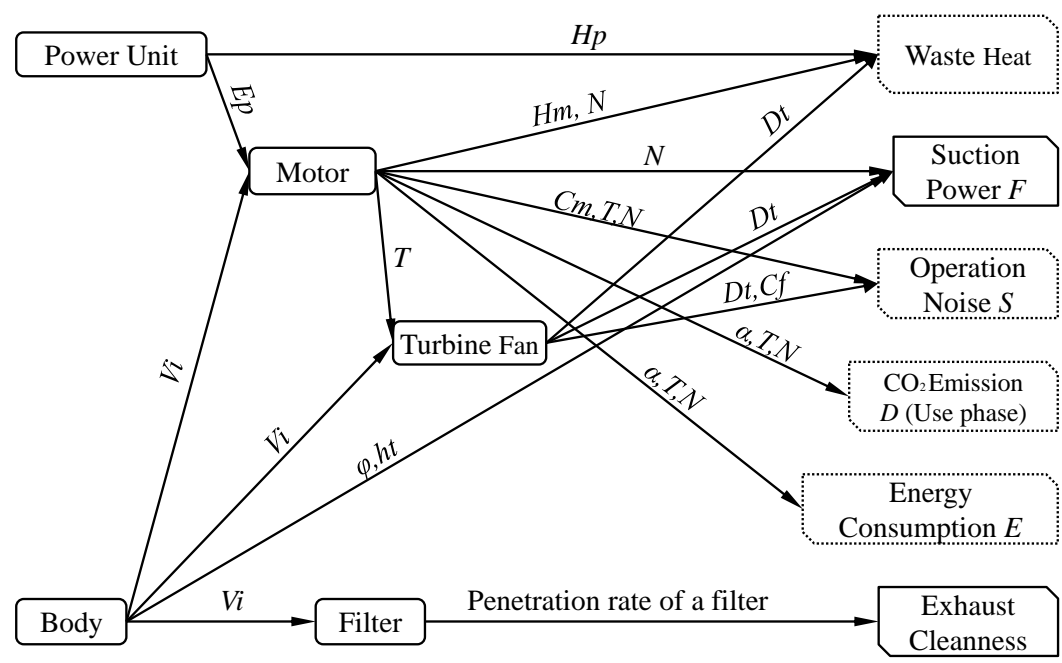

$$
\begin{aligned}
& \mathrm{Hp}: \text { Waste heat of Power Unit } \\
& \mathrm{Hm}: \text { Waste heat of Motor } \\
& \mathrm{Ep}: \text { Electric power } \\
& \mathrm{Vi}: \text { Inner volume of Body } \\
& T: \text { Torque (Motor) } \\
& N: \text { Revolution (Motor) } \\
& \mathrm{Dt}: \text { Diameter of Turbine Fan } \\
& \mathrm{Cf}: \text { Coefficient of noise (Turbine) } \\
& \mathrm{Cm}: \text { Coefficient of noise (Motor) } \\
& \alpha: \text { Energy conversion efficiency } \\
& \varphi: \text { Coefficient of air flow resistance } \\
& h t: \text { Pressure of inside of the Body }
\end{aligned}
$$
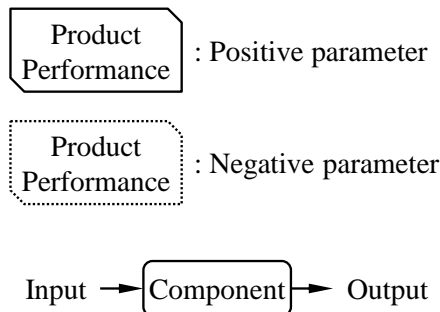

Fig. 2. Function network diagram of a vacuum cleaner and graphical representation of performance criteria (positive and negative) and product components. 


\subsection{Consideration of upgradable performance criteria and components}

Upgradable performance criteria are defined as a product performance upon which consumer emphasis is placed, as evaluated by application of quality function deployment (QFD) or, alternatively, those performance criteria, which have a short value life. Using the function network diagram, a designer searches for components that have close relationships with the chosen upgrade performance criterion and defines those as potential upgradable components. When a plurality of upgradable components are identified, the candidates should be narrowed down by considering the balance between upgrade performance criteria and possible upgrade affected performance criteria and components as described below.

\subsection{Consideration of upgrade affected performance criteria and components}

Upgrade affected performance criteria indicate that the value of performance is changed by exchanging upgrade components. In addition, the authors define a component that has a close relationship with an upgrade affected performance criterion as an upgrade affected component. Upgrade affected performance criteria and components are identified in the same way as upgrade components by using the function network diagram. For example, a designer defines the performance of the suction power as the upgrade performance criterion and the turbine fan component as the upgrade component for the vacuum cleaner described in Figure 2. In this case, the waste heat and operation noise are defined as upgrade affected performance criteria because the upgrade of the turbine fan causes the diameter of turbine fan $D_{t}$ and the coefficient of noise of the turbine $C_{f}$ to increase. Therefore, the power unit and the motor emerge as upgrade affected components. Possible approaches for mitigating this condition can be developed such as building low-level waste heat and low-noise motor into the 1st generation vacuum cleaner, or developing and upgrading a motor that has high suction power, low-level waste heat and a low noise, simultaneously upgrading and changing the motor with the turbine fan. These approaches are narrowed down in the same way as that of the upgrade components.

\subsection{Application of the PSD method and the evaluation of the solution set}

This study applies the PSD method to the proposed method in order to obtain the range of required product performance and functions, and the range of the component design variables that can realize this performance and function range. To obtain these ranged design solutions, the equations and the range of the required product performance and functions and the design variables of the components are needed. The equations show the relationships between product performance and functions and component design variables. In the absence of equations, the designer should define approximate equations based on the performance parameters and design variables in the product and component databases.

Range of the required product performance and functions and the designer configurable range of design variables are configured in accordance with the 
distributions in the product and component roadmaps. A conclusive point-based design proposal is selected from the ranged set of design solutions and a preference number. Under conditions where the design proposal must be modified, the designer should search for the design proposal that satisfies the modified requirements from the ranged set of design solutions. However, in the absence of a design proposal in the ranged set of design solutions, the designer should define the required performance and design variables again and apply them to the PSD system.

\section{Case Study: Application to the Design of a Vacuum Cleaner}

\subsection{Setting the design problem}

This paper shows an application of the proposed method to a vacuum cleaner. According to the cycle of trade up to a new model, the authors hypothesize an upgrade time equivalent to approximately five years (for a consumer trade up proportion of $60 \%$ ) from launch time of the 1st generation product. To understand the trend of performance requirements and design variables, the authors create databases for launched products and components. The product databases include the vacuum cleaners manufactured by three companies (Company A, B, and C) from 2005 to 2013. The component database includes motors manufactured by a single company in 2013 because there is no data for motors manufactured before 2012 .

Figure 2 shows the function network diagram of the vacuum cleaner. Using the result of QFD as shown in Figure 3, this study defines the suction power $F[\mathrm{~W}]$ as an upgrade performance that has a high level of value degradation. Using the information in Figure 2, the motor is configured as an upgrade component. In addition, the operation noise $S[\mathrm{~dB}]$, the amount of $\mathrm{CO}_{2}$ emission $D[\mathrm{~g}]$, the energy consumption $E$ [W], and total production cost as the performance criteria affected by the upgrade are defined. The product performance requirements and the range of design variables based on the product database and roadmap are configured. Finally, the ranged set of design solutions is calculated using the equations between product performance and design variables from the PSD system.

The range of the design variables can increase and decrease relative to the reference values that are assumed to be the design variables of the 1st generation product. The total production cost for the upgraded product has multiple relations with the costs for the upgrade components and the affected components (i.e., the motor and the turbine fan). The assumption is that the cost for the components increases relative to the difference between the design variables of the 1 st generation (reference value) and those of the 2 nd generation. Therefore, the cost for components (not including the motor and the turbine fan) is higher than components without the upgrade. This study assumes that if the range of the design variables decreases, then total production cost increases moderately than is the case for an increase in the range of the design variables. Figure 4 shows the relationship of the production cost for the product with and without the upgrade. 


\begin{tabular}{|c|c|c|c|c|c|c|c|c|c|c|c|c|}
\hline & & \multicolumn{11}{|c|}{ Components } \\
\hline Customer demands & 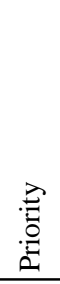 & 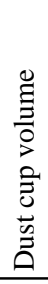 & 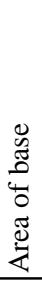 & $\begin{array}{l}\frac{\vec{t}}{00} \\
\frac{.00}{0} \\
3 \\
\frac{\sigma}{0} \\
\stackrel{0}{0}\end{array}$ & 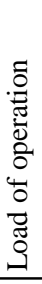 & 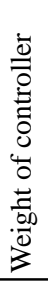 & 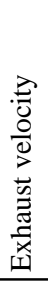 & 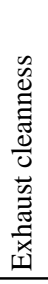 & 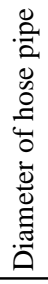 & 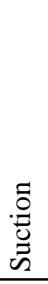 & 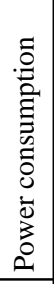 & 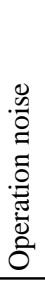 \\
\hline High suction power & 6.3 & & & & & & & & 3 & 9 & & \\
\hline $\begin{array}{l}\text { Easy to clean } \\
\text { a narrow space } \\
\end{array}$ & 6.2 & & & & & & & & & 1 & & \\
\hline Easy to clean & 5.9 & & 3 & 9 & 9 & 3 & & & & 1 & 9 & 3 \\
\hline $\begin{array}{l}\text { Easy to clean } \\
\text { a wooden floor well }\end{array}$ & 5.1 & & & & & & & & & 3 & & \\
\hline Easy to store a cleaner & 4.9 & 9 & 3 & & & & & & & & & \\
\hline Easy to operate a cleaner & 3.6 & & 3 & 9 & 3 & 3 & & & & & & \\
\hline Low operation noise & 3.6 & & & & & & & & 3 & & & 9 \\
\hline Priority & & $\stackrel{\infty}{\sim}$ & 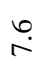 & $\stackrel{0}{\ddot{n}}$ & ฯ & $\stackrel{\circ}{i}$ & $\stackrel{\infty}{\infty}$ & $\stackrel{+}{=}$ & $\ddot{n}$ & $\stackrel{\infty}{\dot{J}}$ & $\ddot{a}$ & $\begin{array}{l}\infty \\
\infty\end{array}$ \\
\hline
\end{tabular}

$9:$ Strong relationship, $3:$ Moderate relationship, $1:$ Weak relationship

Fig. 3. Result of customer demands investigation. [Source: Kobayashi (2003), partially modified]

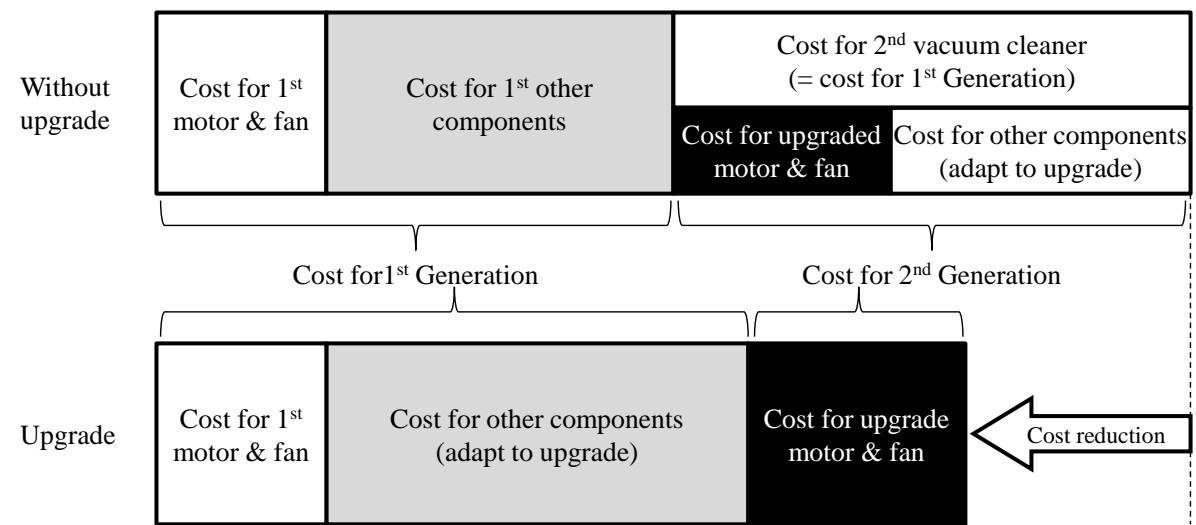

Fig. 4. Comparison of the product costs with and without the upgrade. 
In this application, the authors assume that the product performance and design variables of the components of the 2 nd generation product without an upgrade are equal to the upgraded product's parameter. In addition, the authors assume that the cost of the 2 nd generation without a product upgrade is equal to the 1 st generation without a product upgrade.

This study classifies the customer demands into 3 types as follows:

(1) Performance preferable customer: the customer requires a high suction power

(2) Silence preferable customer: the customer requires a low noise

(3) Energy-saving preferable customer: the customer requires a low energy consumption

\subsection{Discussions}

With respect to the relation between the suction power and the power consumption, and the operation noise, Figure 5 compares the performance-oriented solutions (performance preferable customer), silence-oriented solutions (silence preferable customer), and ecology-oriented solutions (energy-saving preferable customer). Figure 5 indicates that ecology-oriented solutions satisfy the required performance for the silence preferable customer. The result indicates the designer can define the customer demands as the demands for the performance preferable customer and the energy-saving preferable customer.

In this study, a ranged set of product design solutions that include various performance criteria, cost, and environmental loads in use concurrently with the consideration of future uncertain design information are obtained.

Figure 6 shows the comparison of the cost for each customer demand. The results suggest that the total production cost of the upgraded product is reduced by about $25 \%$ compared with that of the product without upgrade, and that suction power satisfies the required range. Therefore, this study concludes that the proposed method can obtain a ranged set of product design solutions in consideration of performance criteria, cost, and environmental load for various customer demands. However, the designers should define the increasing rate of 1 st generation production costs of the upgraded product that customers allow to consume because the 1st generation production cost of the upgraded product increases from $22.4 \%$ to $27.6 \%$. Also the application of this increasing rate to the requirements of the upgraded product should be done. 


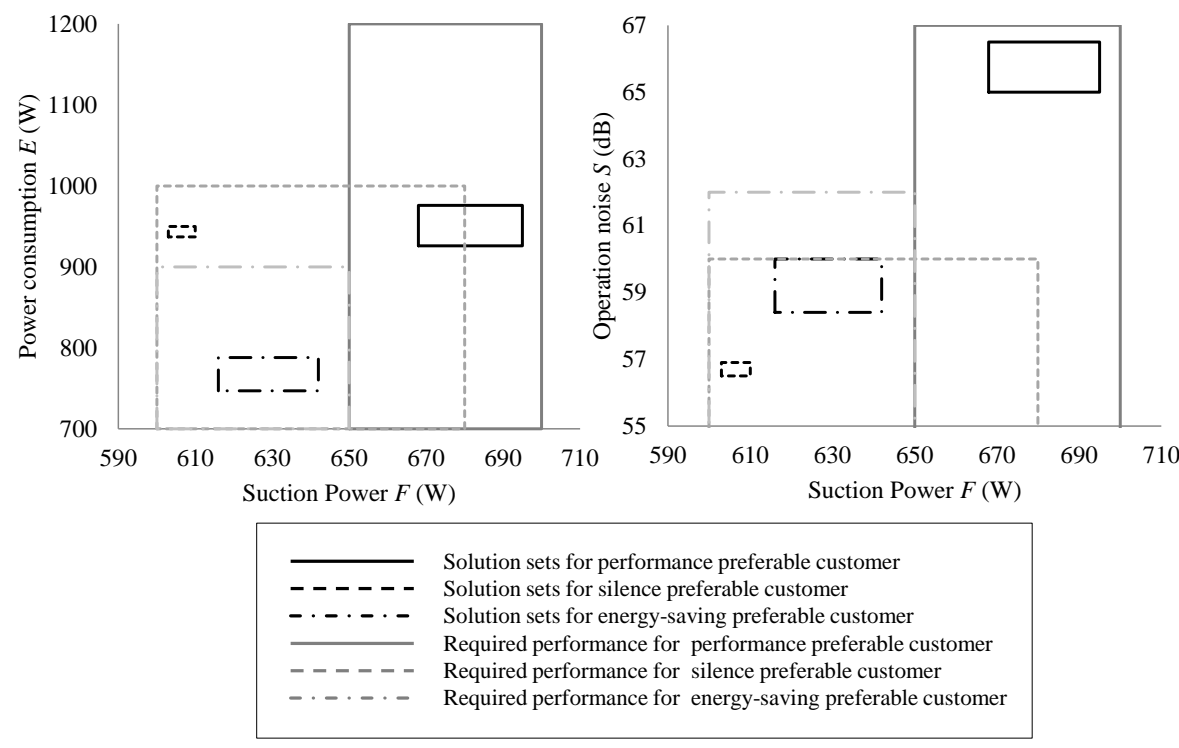

Fig. 5. Comparison of the solution areas of each customer demands.

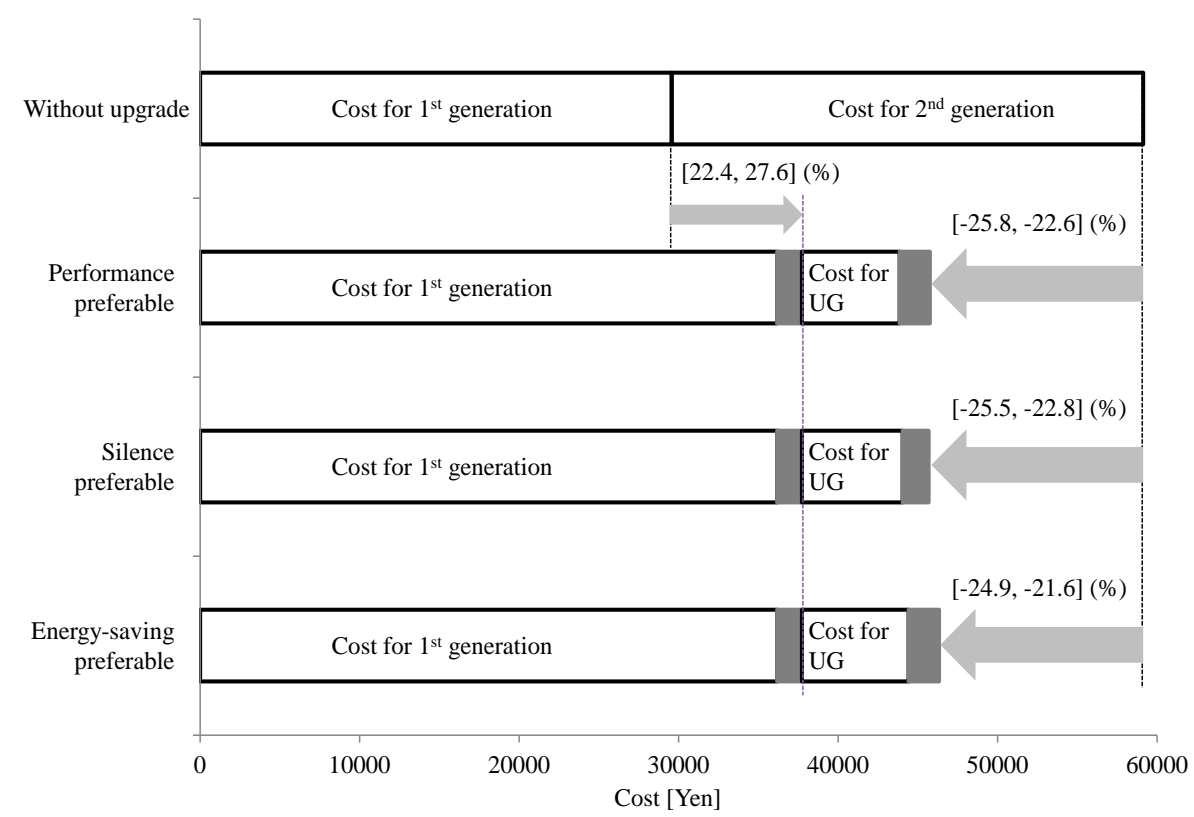

Fig. 6. Comparison of the cost for each customer demands. 


\section{Conclusions}

This paper proposed a design method that can obtain a ranged set of solutions that satisfies multiple product performance criteria, cost, and environmental load by considering uncertain design information for various customer demands. To obtain the ranged set of solutions, PSD method is applied to the proposed method that proposes to increase product value and extend product life by exchanging components whose value has diminished below a threshold value. In addition, the authors proposed the function network diagram to define the product performance criteria and components that possess a short value life. This paper showed the usefulness of this diagram by application.

In this paper, the ranged set of requirements that include future uncertainty is predicted arbitrarily based on the distribution of the product roadmap. Moreover, this prediction needs the designer's knowledge and experience. Therefore, predicting the ranged set of requirements logically is one of the subjects of future study. In addition, the authors also need to indicate the business model for familiarizing the concept of the product upgradability.

Acknowledgments. This work was partially supported by Research Project Grant by Institute of Science and Technology, Meiji University.

\section{References}

1. Ministry of the Environment in Japan: Kyoto Protocol Target Achievement Plan, Ministry of the Environment of Japan, (2008)

2. Kobayashi, H.: Product Lifecycle Planning, pp. 103--130. Ohmsha, in Japanese, (2003)

3. Shimomura, Y., Kondoh, S., Umeda, Y.: Proposal of an Upgrade Planning Method for Upgradeable Product Design, Transactions of the Japan Society of Mechanical Engineers, Series (C), vol. 72, no. 713, pp.282--289 (2006)

4. Fukushige S., Arino M., Umeda Y.: Computer-Aided Design for Product Upgradability under Geometric Constraints. In: Matsumoto, M., Umeda, Y., Fukushige, S. (eds.) Design for Innovative Value Towards a Sustainable Society, pp. 828--831. Springer, Netherland (2011)

5. Inoue, M., Nahm, Y-E., Okawa, S., Ishikawa, H.: Design Support System by Combination of 3D-CAD and CAE with Preference Set-based Design Method, Concurrent Engineering: Research and Applications, vol. 18, no. 1, pp.41--53 (2010)

6. Inoue M., Nahm Y.-E., Tanaka K., Ishikawa H.: Collaborative Engineering among Designers with Different Preferences: Application of the Preference Set-Based Design to the Design Problem of an Automotive Front-Side Frame, Concurrent Engineering: Research and Applications, vol. 21, no. 4, pp. 252--267 (2013)

7. Murakami, T., Inoue, M., Nahm, Y-E., Ishikawa, H.: An Upgrade Design Method for Environmental Issues Based on the Concept of Set-Based Design. In: Matsumoto, M., Umeda, Y., Fukushige, S. (eds.) Design for Innovative Value Towards a Sustainable Society, pp.500--505. Springer, Netherland (2011) 